\title{
Restoration of $m i R-145$ expression suppresses cell proliferation, migration and invasion in prostate cancer by targeting FSCN1
}

\author{
MIKI FUSE ${ }^{1,2}$, NIJIRO NOHATA ${ }^{1}$, SATOKO KOJIMA ${ }^{3}$, SHINICHI SAKAMOTO ${ }^{2}$, TAKESHI CHIYOMARU ${ }^{4}$, \\ KAZUMORI KAWAKAMI ${ }^{4}$, HIDEKI ENOKIDA ${ }^{4}$, MASAYUKI NAKAGAWA ${ }^{4}$, \\ YUKIO NAYA $^{3}$, TOMOHIKO ICHIKAWA ${ }^{2}$ and NAOHIKO SEKI ${ }^{1}$ \\ Departments of ${ }^{1}$ Functional Genomics and ${ }^{2}$ Urology, Chiba University Graduate School of Medicine; \\ ${ }^{3}$ Department of Urology, Teikyo University Chiba Medical Center, Chiba; ${ }^{4}$ Department of Urology, \\ Graduate School of Medical and Dental Sciences, Kagoshima University, Kagoshima, Japan
}

Received October 12, 2010; Accepted December 3, 2010

DOI: $10.3892 /$ ijo.2011.919

\begin{abstract}
MicroRNAs (miRNAs) are small non-coding RNAs that regulate gene expression, primarily at the posttranscriptional level. Growing evidence suggests that miRNAs function as oncogenes or tumor suppressors in human cancers. The down-regulation of $m i R-145$ has been reported in many types of human cancer, including prostate cancer (PC), suggesting that $m i R-145$ functions as a tumor suppressor. Using the PC cell lines, PC3 and DU145, gain-of-function assays revealed that $m i R-145$ transfection inhibited cell proliferation, migration and invasion. Fascin homolog 1 (FSCN1), an actin-bundling protein, is a candidate target gene of $m i R-145$ based on genome-wide gene expression analysis. A luciferase reporter assay showed a significantly decreased signal at two miR-145 target sites at the 3'UTR of FSCN1, suggesting that miR-145 directly regulates FSCN1. In FSCN1 loss-of-function assays, cell growth, migration and invasion were all inhibited, implying that FSCN1 is associated with the progression of $\mathrm{PC}$. The identification of tumor suppressive miRNAs and their target genes could provide new insights into the potential mechanisms of prostate carcinogenesis.
\end{abstract}

\section{Introduction}

Prostate cancer (PC) remains one of the most prevalent cancers and a major cause of morbidity and mortality in the western world (1-4). In 2007, 220,000 new patients were diagnosed with $\mathrm{PC}$ and $\sim 27,000$ cancer-related deaths were

Correspondence to: Dr Naohiko Seki, Department of Functional Genomics, Chiba University Graduate School of Medicine, 1-8-1 Inohana Chuo-ku, Chiba 260-8670, Japan

E-mail: naoseki@faculty.chiba-u.jp

Key words: $m i R-145$, prostate cancer, fascin homolog 1, tumor suppressor reported (5). Disease progression and the development of hormone refractory disease remain major causes of cancerrelated death. In order to significantly alter the disease course, improvements should be made in the understanding, diagnosis, and treatment of aggressive forms of metastatic PC.

MicroRNAs (miRNAs) are small, non-coding RNAs with a length of $\sim 22$ nucleotides. They regulate gene expression by promoting mRNA cleavage and at the post-transcriptional level, by translational suppression (6). They play important roles in various biological and metabolic processes, including development, differentiation, signal transduction, cell maintenance and cancer $(6,7)$. Bioinformatic predictions indicate that miRNAs regulate $>30 \%$ of the protein coding genes (8). It is estimated that $\sim 1,000$ miRNAs exist in the vertebrate genome. So far, 1,048 human miRNAs have been registered in miRBase release 16.0 (http://microrna.sanger.ac.uk/).

An important role for miRNAs in the development of cancer has emerged over the years. miRNAs are aberrantly expressed in many human cancers, and they can function as oncogenes or tumor suppressors. Up-regulated miRNAs can function as oncogenes by negatively regulating tumor suppressor genes, while down-regulated miRNAs can act as tumor suppressors, inhibiting cancers by regulating oncogenes. A growing body of evidence indicates that unique miRNA expression profiles are associated with particular cancers. These profiles could serve as useful biomarkers for the diagnosis and prognosis of disease $(9,10)$. Studies have been carried out for the purpose of identifying specific miRNA alterations in various cancers, including PC (11-16).

$m i R-145$ has frequently been reported to be down-regulated in cancers, including prostate (17), bladder (18), colon (19), ovary (20) and esophageal cancer (21), as well as B-cell malignancies (22). $m i R-145$ is located on chromosome 5q32-33 within a $4.09 \mathrm{~kb}$ region (http://microrna.sanger.ac.uk/). Of interest, $5 \mathrm{q} 31.1$ is a well-known fragile site in the human genome (http://www.genenames.org/) and is often deleted in cancers. Increasing evidence indicates that $m i R-145$ acts as a tumor suppressive miRNA which inhibits cell growth, invasion and migration in cancer cells (23).

While data suggest that $m i R-145$ plays a role in PC, there is limited knowledge of its targets. In this study, we focused 
on the target identification of $m i R-145$ in PC, based on gene expression analysis of $m i R-145$ transfectants. We demonstrate that miR-145 targets fascin homolog 1 (FSCN1) and that silencing FSCNI reveals its function as an oncogene in PC.

\section{Materials and methods}

Cell lines and cell culture. The human PC cell lines, PC3 and DU145, were obtained from the American Type Culture Collection (Manassas, VA, USA). The PC cell lines were cultured in monolayers in RPMI-1640 medium supplemented with $10 \%$ fetal bovine serum, and maintained in an incubator with a humidified atmosphere of $95 \%$ air and $5 \% \mathrm{CO}_{2}$ at $37^{\circ} \mathrm{C}$.

RNA isolation. Total RNA was isolated using TRIzol reagent (Invitrogen, Carlsbad, CA, USA) according to the manufacturer's instructions. RNA concentrations were determined spectrophotometrically, and molecular integrity was checked by gel electrophoresis. RNA quality was confirmed using an Agilent 2100 Bioanalyzer (Agilent Technologies, Santa Clara, CA).

Normal prostate RNAs were purchased as follows: Prostate-1 (Clontech Human Prostate Total RNA, no. 636550) and prostate-2 (Biochain Total RNA-Human Adult Normal Tissue, no. R1234201-50).

Mature miRNA transfection. Mature miRNA molecules, Pre-miR ${ }^{\mathrm{TM}}$ miRNA Precursors, and a negative control (hsamiR-145; P/N: AM17100 and negative control miRNA; P/N: AM17111; Applied Biosystems, Foster City, CA, USA) were incubated with Opti-MEM (Invitrogen) and Lipofectamine ${ }^{\mathrm{TM}}$ RNAiMax reagent (Invitrogen) as described previously (24). We first confirmed the transfection efficiency of Pre-miR in the cell lines based on the down-regulation of PTK9 mRNA by transfection with $m i R-1$ (as recommended by the manufacturer). Under our experimental conditions, the efficiency with which miRNA was transfected into PC cells was similar to our previous experiments and sufficient for experimental analysis.

Cell proliferation, migration and invasion assays. Cells were transfected with $10 \mathrm{nM}$ miRNA by reverse transfection and plated in 96-well plates at $3 \times 10^{3}$ cells per well. After $72 \mathrm{~h}$, cell proliferation was determined by the XTT assay, using the Cell Proliferation Kit II (Roche Molecular Biochemicals, Germany) as described previously $(21,25)$. Triplicate wells were measured for cell viability in each treatment group. Cell migration activity was evaluated by wound-healing assays. Cells were plated in six-well dishes, and the cell monolayer was scraped using a micropipette tip. The initial gap width $(0 \mathrm{~h})$ and the residual gap width, $24 \mathrm{~h}$ after wounding, were calculated from photomicrographs as described previously $(18,21)$. A cell invasion assay was carried out using modified Boyden chambers containing transwell-precoated Matrigel membrane filter inserts with $8-\mu \mathrm{m}$ pores in 24-well tissue culture plates (BD Biosciences, Bedford, MA, USA), as described previously $(18,21)$. All experiments were performed in triplicate.
Target gene search for $m i R-145$. In order to identify the target genes of $m i R-145$ in the PC cell lines, PC3 and DU145, we performed genome-wide screening using $m i R-145$ transfectants compared to the miRNA-negative control transfectants. Oligo Microarray Human 44K (Agilent Technologies) was used for expression profiling in miR-145transfected PC3 and DU145 cells in comparison to miRnegative-control transfectants, as described previously $(18,21,25)$. Briefly, hybridization and washing steps were performed as described previously (26). The arrays were scanned using a Packard GSI Lumonics ScanArray 4000 (Perkin-Elmer, Boston, MA, USA). The data obtained were analyzed by means of DNASIS array software (Hitachi Software Engineering, Tokyo, Japan), which converted the signal intensity for each spot into text format. The $\log _{2}$ ratios of the median subtracted background intensities were analyzed. Data from each microarray study were treated with a global normalization method as described previously (26).

The predicted target genes and their conserved miRNA binding site seed regions were investigated using TargetScan (release 5.1, http://www.targetscan.org/). The sequences of the predicted mature miRNAs were confirmed using miRBase (release 16.0, http://microrna.sanger.ac.uk/).

Real-time quantitative $R T-P C R$. First-strand cDNA was synthesized from $1 \mu \mathrm{g}$ total RNA using random primers and the Reverse Transcription (RT) System (Promega, Tokyo, Japan). Gene-specific PCR products were assayed continuously using a 7900-HT Real-Time PCR System according to the manufacturer's instructions. The initial PCR step consisted of a 10 -min hold at $95^{\circ} \mathrm{C}$, followed by 40 cycles of 15-sec denaturation at $95^{\circ} \mathrm{C}$ and 1 -min annealing/extension at $63^{\circ} \mathrm{C}$. TaqMan ${ }^{\circledR}$ probes and primers for $F S C N 1(\mathrm{P} / \mathrm{N}$ : Hs00979631_g1) were used (Assay-On-Demand Gene Expression Products; Applied Biosystems). Glyceraldehyde-3phosphate dehydrogenase (GAPDH) (A/N: NM_002046) or 18S (A/N: NR_003286) was used as the internal control (Assay-On-Demand Gene Expression Products; Applied Biosystems). The expression levels of $m i R-145(\mathrm{P} / \mathrm{N}$ : 4427975) were analyzed by TaqMan quantitative real-time PCR (TaqMan ${ }^{\circledR}$ MicroRNA Assay; Applied Biosystems) and normalized to $R N U 6 B(\mathrm{~A} / \mathrm{N}: \mathrm{K} 03099)$. All reactions were performed in triplicate, and included negative control reactions that lacked cDNA.

Immunoblotting. Cells were harvested $72 \mathrm{~h}$ after transfection. Protein lysates $(50 \mu \mathrm{g})$ were separated by NuPAGE on a 4$12 \%$ bis-Tris gel (Invitrogen) and transferred onto PVDF membranes. Immunoblotting was performed with diluted (1:100) monoclonal FSCN1 antibody (ab49815, Abcam, Cambridge, UK), with GAPDH antibody (MAB374; Chemicon, Temecula, CA, USA) used as the internal control. The membrane was washed and then incubated with goat anti-mouse IgG $(\mathrm{H}+\mathrm{L})$-HRP conjugate (Bio-Rad, Hercules, $\mathrm{CA}$ ). Specific complexes were visualized by echochemiluminescence (GE Healthcare Bio-Sciences, Princeton, NJ).

Plasmid construction and dual-luciferase assay. miR-145 target sequences were chemically synthesized (Takara, Japan) and inserted between the XhoI and PmeI restriction 
A

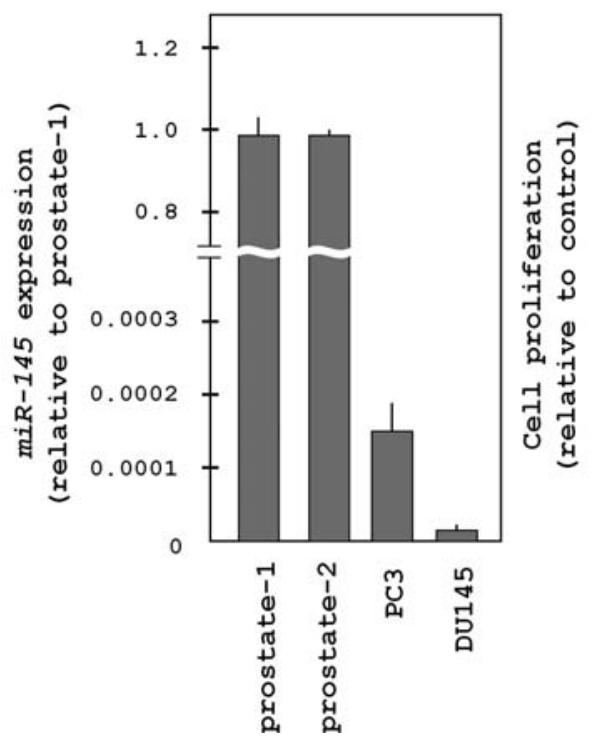

B

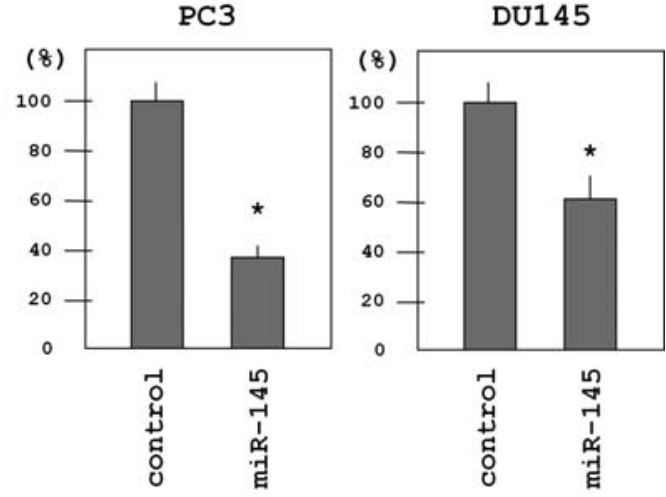

Figure 1. miR-145 expression levels and cell proliferation. (A) The expression level of $m i R-145$ in normal prostate tissues and the PC cell lines, PC3 and DU145. Real-time RT-PCR showed that the expression level of miR-145 in PC cell lines was significantly lower than that in normal prostate tissues. The results were normalized to $R N U 6 B$ expression and are presented as relative to the normal tissue, prostate-1. (B) Reduced proliferation of cells was observed in PC3 and DU145 cell lines transfected with $m i R-145 .{ }^{*} \mathrm{p}<0.05$.

sites in the 3'UTR of the hRluc gene in the psiCHECK-2 vector (Promega). The amplified fragment was cloned into the psiCHECK-2 vector and confirmed by sequencing using the following primers: 116-123F, GATCGCTCGAGACTC CTGTGGACTTCTTCTTCG; 116-123R, CTCTAGGTTT AAACGCGGAGAAGGGGTTAGCA; 377-384F, CGAT CGCTCGAGTCTGGCACCTCTTTCTTCTGA; 377-384R, GGCCGCTCTAGGTTTAAACGACATGTGCCCAGCTCT CCT; 729-735F, GATCGCTCGAGCTGCACGTTCTGCCA AGGT; 729-735R, GCTCTAGGTTTAAACGGACGCCT CCAGCAATAATA; 1140-1147F, GATCGCTCGAGCTCT GGGTGTCTTGGTCTT; and 1140-1147R, CGCTCTAGG TTTAAACGGGGCTGCAGACTGAGTTAT.

PC3 cells were then transfected with $5 \mathrm{ng}$ vector, $10 \mathrm{nM}$ mature miRNA molecules, Pre-miRNA ${ }^{\mathrm{TM}}$ miR-145 (Applied Biosystems), and $1 \mu 1$ Lipofectamine 2000 (Invitrogen) in $100 \mu 1$ Opti-MEM $^{\mathrm{TM}}$. Firefly and Renilla luciferase activities in cell lysates were determined using a dual-luciferase assay system (Promega). Normalized data were calculated as the quotient of Renilla/firefly luciferase activities.

Small interfering (si)RNA treatment. After co-transfecting 10 nM small interfering RNA si-FSCN1 (J-019576-08; Thermo Fisher Scientific, Waltham, MA, USA) or negativecontrol siRNA (D-001810-10; Thermo Fisher Scientific), PC cells were seeded into 96 -well plates at $3 \times 10^{3}$ cells per well. After $72 \mathrm{~h}$, cell proliferation, cell migration and cell invasion assays were performed. Triplicate wells were measured for cell viability in each treatment group.

Statistical analysis. The relationships between two groups and the numerical values obtained by real-time RT-PCR were analyzed using the non-parametric Mann-Whitney U test. Expert StatView (version 4, SAS Institute Inc., Cary,
NC, USA) analysis software was used, and statistical significance was defined as a p-value of $<0.05$.

\section{Results}

Effect of miR-145 transfection on cell proliferation in PC cell lines. We first examined the expression levels of $m i R-145$ in PC cell lines compared to normal prostate tissues. The expression levels of miR-145 were extremely low in both the PC cell lines, PC3 and DU145, compared to the normal prostate tissues (Fig. 1A), suggesting that the endogenous $m i R-145$ in those cell lines does not affect cell viability. Therefore, we performed gain-of-function studies using mature $m i R-145$. The XTT cell proliferation assay showed significant cell growth inhibition in $m i R-145$ transfectants in both the PC3 and DU145 cells compared to the control transfectants (PC3, 32.5\% of control, p $<0.01$; DU145, 62.8\% of control, p<0.01) (Fig. 1B). The remarkable cell growth inhibition was particularly evident in PC3 cells.

Identification of miR-145 target genes by genome-wide gene expression analysis. In order to investigate the molecular basis of miR-145 tumor suppression in PC cells, we examined the effect of miR-145 on protein-coding genes. Mature miR-145 was transiently transfected into PC3 and DU145 cells, with negative-miRNA transfection used as the control. Comprehensive gene expression analysis (see Materials and methods) clearly showed changes in gene expression patterns between $m i R-145$ and negative-control transfectants. In order to identify candidate $m i R-145$ target genes, a cut-off value of $<-1.00$-fold was applied to the array data. This filtering resulted in the identification of 20 genes that were significantly down-regulated upon $m i R-145$ transfection in both the PC3 and DU145 cells (Table I). 
Table I. Top 20 genes that were down-regulated by $>0.5$-fold in miR-145-transfected PC3 and DU145 cells in comparison to the control.

\begin{tabular}{|c|c|c|c|c|c|c|}
\hline $\begin{array}{l}\text { Entrez } \\
\text { gene ID }\end{array}$ & Gene symbol & Gene name & $\begin{array}{c}\log _{2} \text { ratio } \\
\text { (PC3) }\end{array}$ & $\begin{array}{c}\log _{2} \text { ratio } \\
(\mathrm{DU} 145)\end{array}$ & $\begin{array}{c}\log _{2} \text { ratio } \\
\text { (average) }\end{array}$ & $\begin{array}{c}\text { Number of } \\
m i R-145 \\
\text { target site }\end{array}$ \\
\hline 6624 & FSCN1 & Fascin homolog 1, actin-bundling protein & -2.33 & -2.07 & -2.20 & 4 \\
\hline 1979 & EIF4EBP2 & Eukaryotic translation initiation factor $4 \mathrm{E}$ binding protein 2 & -2.86 & -1.06 & -1.96 & 1 \\
\hline 1066 & CES1 & Carboxylesterase 1 (monocyte/macrophage serine esterase 1 ) & -2.46 & -1.26 & -1.86 & - \\
\hline 7170 & TPM3 & Tropomyosin 3 & -2.36 & -1.26 & -1.81 & - \\
\hline 29943 & $P A D I 1$ & Peptidyl arginine deiminase, type I & -2.32 & -1.12 & -1.72 & - \\
\hline 92675 & DTD1 & D-tyrosyl-tRNA deacylase 1 homolog (S. cerevisiae) & -1.86 & -1.12 & -1.49 & 1 \\
\hline 50848 & $F 11 R$ & F11 receptor & -1.58 & -1.26 & -1.42 & 2 \\
\hline 4312 & $M M P 1$ & Matrix metallopeptidase 1 (interstitial collagenase) & -1.79 & -1.04 & -1.41 & - \\
\hline 58527 & C6orf115 & Chromosome 6 open reading frame 115 & -1.36 & -1.42 & -1.39 & 1 \\
\hline 54538 & $\mathrm{ROBO4}$ & Roundabout homolog 4, magic roundabout (Drosophila) & -1.25 & -1.41 & -1.33 & - \\
\hline 3920 & $L A M P 2$ & Lysosomal-associated membrane protein 2 & -1.48 & -1.13 & -1.31 & 2 \\
\hline 4188 & $M D F I$ & MyoD family inhibitor & -1.35 & -1.21 & -1.28 & 1 \\
\hline 7374 & $U N G$ & Uracil-DNA glycosylase & -1.32 & -1.15 & -1.24 & 1 \\
\hline 114990 & VASN & Vasorin & -1.38 & -1.00 & -1.19 & 1 \\
\hline 23075 & SWAP70 & SWAP switching B-cell complex $70 \mathrm{kDa}$ subunit & -1.20 & -1.14 & -1.17 & 2 \\
\hline 780 & $D D R 1$ & Discoidin domain receptor tyrosine kinase 1 & -1.13 & -1.14 & -1.14 & - \\
\hline 100130009 & LOC 100130009 & Hypothetical LOC100130009 & -1.08 & -1.15 & -1.11 & - \\
\hline 6710 & $S P T B$ & Spectrin, $\beta$, erythrocytic & -1.08 & -1.10 & -1.09 & 1 \\
\hline 4697 & NDUFA4 & NADH dehydrogenase (ubiquinone) $1 \alpha$ subcomplex, 4, $9 \mathrm{kDa}$ & -1.01 & -1.16 & -1.08 & 2 \\
\hline
\end{tabular}

A

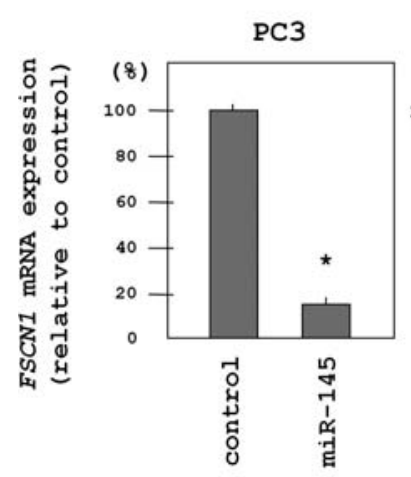

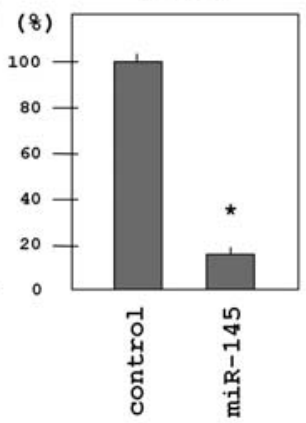

B

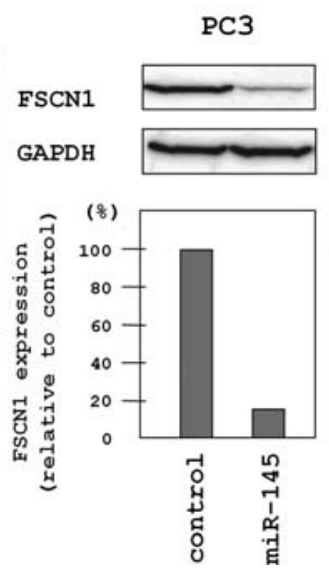

DU145
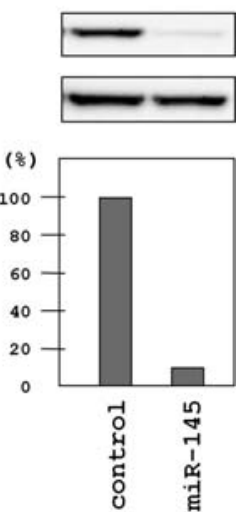

Figure 2. Down-regulated expression of the FSCN1 gene and FSCN1 protein in PC3 and DU145 cells by $m i R-145$ transfection. (A) FSCN1 mRNA expression after transfection of miR-145 for $72 \mathrm{~h}$. FSCN1 mRNA expression was reduced in miR-145 transfectants. FSCN1 mRNA expression levels were measured by TaqMan quantitative real-time PCR in PC3 and DU145 cells. The results were normalized to glyceraldehyde-3-phosphate dehydrogenase (GAPDH) expression. ${ }^{*} \mathrm{p}<0.05$. (B) FSCN1 protein expression was analyzed by Western blot analysis after transfection of miR-145 for 72 h. FSCN1 protein expression was also reduced in miR-145 transfectants. The membranes were blotted with anti-FSCN1 IgG and anti-GAPDH was used as the loading control. The density of each protein band was quantified using NIH-ImageJ. The results were standardized against the levels of GAPDH.

The 3'UTR regions of these down-regulated genes were examined for $m i R-145$ target sites using the TargetScan database (release 5.1, http://www.targetscan.org/). Of the top 20 putative gene targets, 12 genes contained $m i R$ - 145 target sites (Table I).
FSCN1 as a target of post-transcriptional repression by miR-145. We focused on FSCN1 as it was listed as the top candidate gene for $m i R-145$ in the genome-wide gene expression analysis. The expression level of FSCN1 mRNA was significantly decreased by $m i R-145$ transfection in both 


\section{3'UTR of FSCN1}
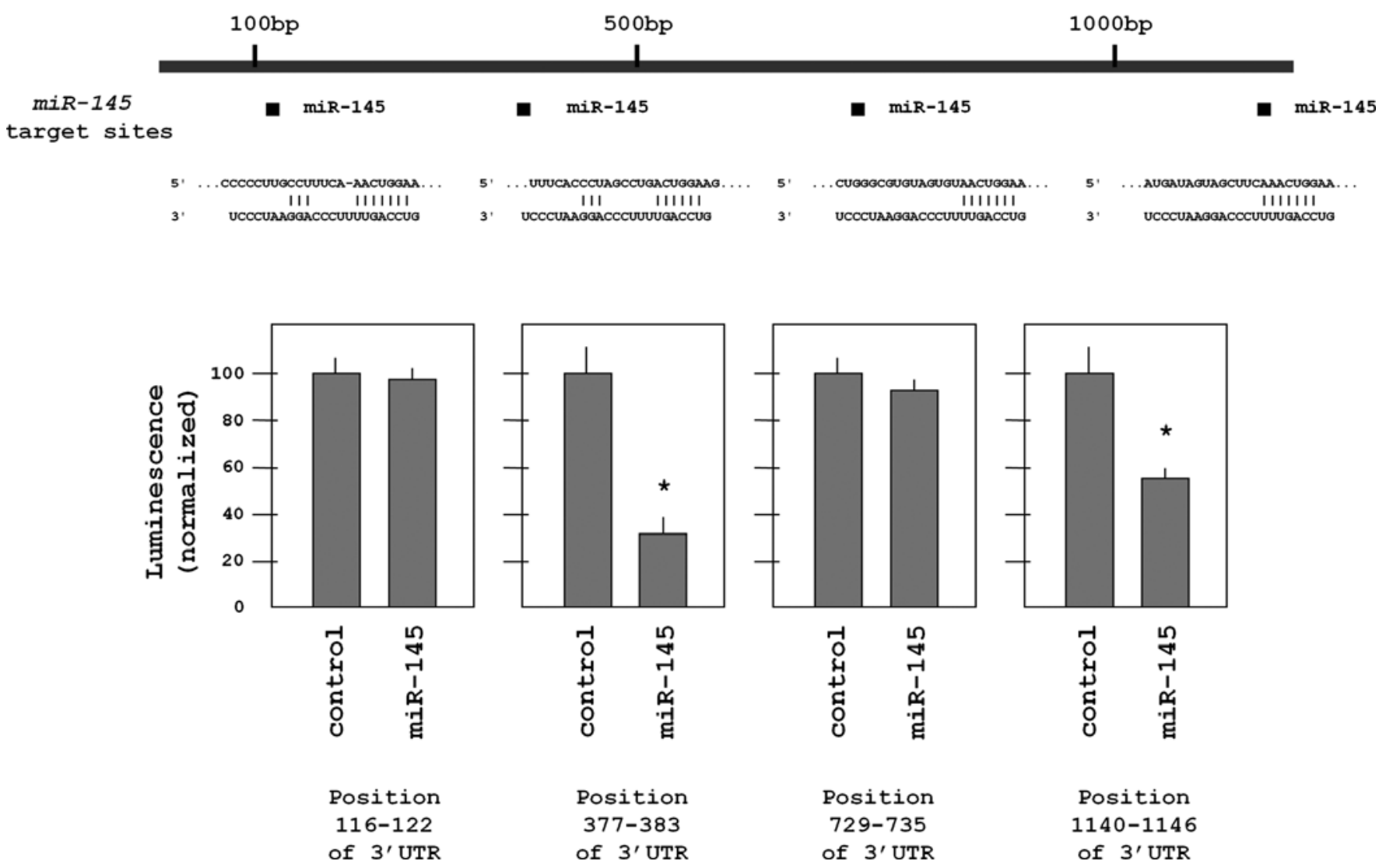$$
\text { of } 3^{\prime} \text { UTR }
$$

Figure 3. miR-145 regulates FSCN1 expression in the PC cell line, PC3, at the mRNA and post-transcriptional level by targeting the 3'UTR of FSCN1 mRNA. (Upper panel) Schema for putative conserved binding sites of miR-145. Putative conserved target sites in the FSCN1 3'UTR were identified with the TargetScan database: The four miR-145 conserved sites are indicated. (Lower panel) PC3 cells were transfected with 5 ng of target FSCN1 3'UTR in a vector construct and $10 \mathrm{nM}$ of miRNA or the negative control. Renilla luciferase activity was measured following a 24-h transfection. The results were normalized against firefly luciferase values.

PC cell lines (Fig. 2A). The protein expression level of FSCN1 was also markedly reduced in the PC cell lines after miR-145 transfection (Fig. 2B).

PC3 cells were used to determine whether the suppression of $m i R-145$ affected FSCN1 expression. The TargetScan database (release 5.1, http://www.targetscan.org/) showed that four conserved sites were expected in the 3'UTR of FSCN1 (Fig. 3, upper panel). The luciferase reporter assay confirmed that the 3'UTR of FSCN1 contained actual targets of $m i R-145$. Specifically, luciferase activity was significantly decreased at two of the four predicted sites (positions 377-383 and 1140-1146 in the 3'UTR of FSCN1) (Fig. 3, lower panel).

Effect of FSCN1 knockdown on cell proliferation, migration and invasion activities in PC cell lines. We examined the expression levels of FSCN1 in PC cell lines, using normal prostate tissues as the controls. The mRNA expression levels of FSCN1 were determined by quantitative real-time RTPCR analysis. The expression levels of FSCN1 in the PC3 and DU145 cells were markedly higher than in the normal tissues (Fig. 4A). A loss-of-function assay using siRNA analysis was performed to examine the oncogenic function of FSCN1 that was directly targeted by $m i R-145$. We investigated whether si-FSCN1 reduced both mRNA and protein expression levels in PC3 and DU145 transfectants. After a 72-h transfection, FSCN1 mRNA and FSCN1 protein were successfully reduced by si-FSCN1 (Fig. 4B and C).

The XTT assay revealed significant cell growth inhibition in si-FSCN1 transfectants (Fig. 5A). The wound healing assay (measuring \% of wound closure) demonstrated that si-FSCN1 inhibited cell migration in PC3 $(60.3 \pm 3.2$ of the control) and DU145 (74.1 \pm 1.7 of the control) (Fig. 5B). The Matrigel invasion assay showed that the number of invading cells was significantly decreased in both si-FSCN1 transfectants: PC3

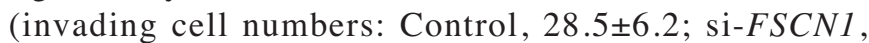

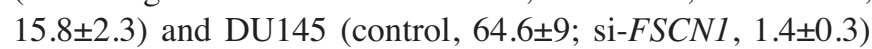
(Fig. 5C).

\section{Discussion}

Treatments available for organ-confined PC include radical prostatectomy, irradiation, or hormonal therapy. A subset of PC patients is prone to disease relapse and metastasis, which frequently progresses to advanced disease even after surgery and can be the cause of death. Therefore, a number of alternative ways for controlling PC have emerged. Expression signatures have shown that miRNAs are dysregulated in a wide variety of human cancers. The fact that miRNAs function 
A

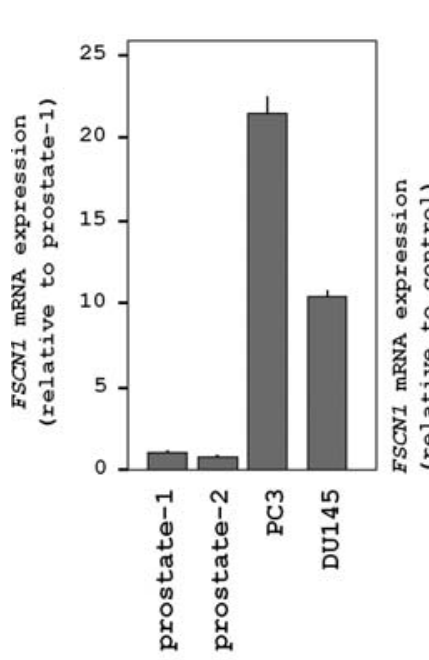

B

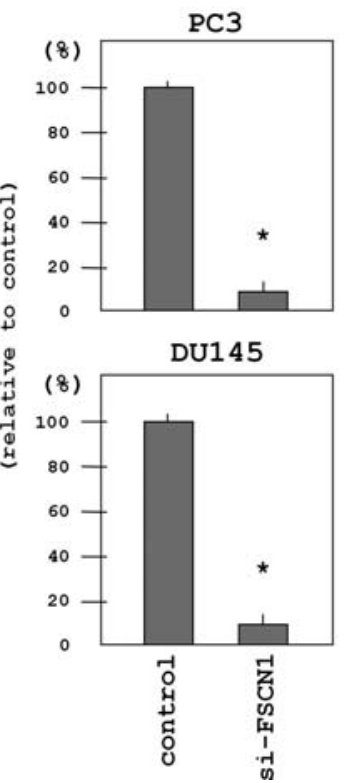

C

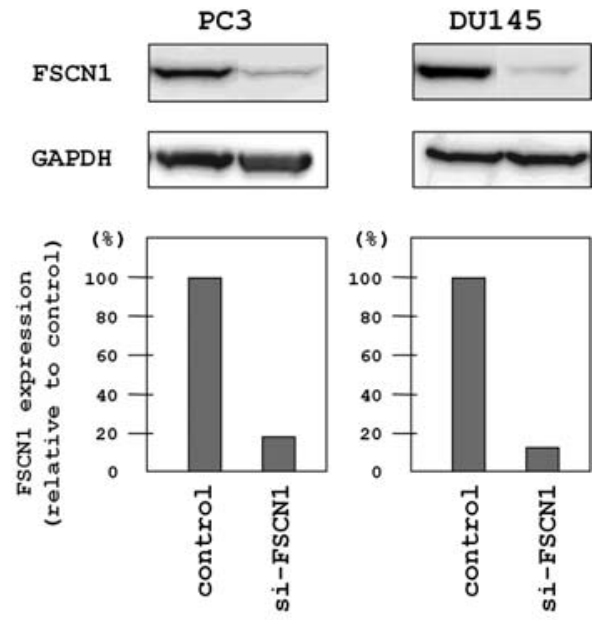

Figure 4. Effects of FSCN1 expression in PC cells following siRNA transfection. si-FSCN1 was transfected into the PC cell lines, PC3 and DU145. (A) The mRNA expression level of FSCN1 in normal prostate tissues and the PC cell lines, PC3 and DU145. Real-time RT-PCR showed that the mRNA expression level of FSCN1 in PC cell lines was significantly lower than that in normal tissues. The results were normalized to 18S RNA expression and are presented as relative to the normal prostate tissue, protate-1. (B and C) Following a 72-h transfection, total RNA and cellular protein were isolated and evaluated by TaqMan quantitative real-time PCR and Western blot analysis, respectively. The results were normalized to glyceraldehyde-3-phosphate dehydrogenase $(G A P D H)$ expression and are presented as relative to the control. GAPDH was used as the immunoblot loading control.

as either oncogenes or tumor suppressors has generated great interest in their possible use as novel targets or tools for anticancer therapies.

Many studies have been carried out to identify differentially expressed miRNAs in PC based on genome-wide miRNA expression profiling (9,11-16). Using micro-dissected malignant and uninvolved areas from 40 prostatectomy specimens, five miRNAs (miR-23b, miR-100, miR-145, $m i R-221$ and $m i R-222)$ were found to be significantly downregulated in malignant tissues compared to normal tissues (16). More recent data using matched tumor and adjacent normal tissues obtained from 76 patients identified 15 differentially expressed miRNAs: $m i R-16, m i R-31, m i R-125 b$, miR-145, miR-149, miR-181b, miR-184, miR-205, miR-221 and $m i R-222$ were down-regulated, whereas $m i R-96, m i R-182$, $m i R-182 *, m i R-183$ and $m i R-375$ were up-regulated (15). In comparative miRNA expression studies, several important miRNAs, such as miR-145, in PC initiation, development and metastasis, have been identified.

Recently, the down-regulation of $m i R-145$ in different types of tumors suggests its role in controlling cell proliferation, migration and invasion (23). The first report of tumor suppression by $m i R-145$ came from studies on colon cancer and demonstrated that $m i R-145$ inhibited cell growth by targeting insulin receptor substrate 1 (27). $m i R-145$ can also impact cell migration and invasion. Using the expression profile of $m i R-145$ in different metastatic breast cancer cell lines, it was evident that cell invasion was reduced by the miR-145-mediated suppression of the metastasis gene mucin1 (28). It has been reported that the lower expression of $m i R-145$ is due to the methylation of the promoter region of
miR-145 in PC cell lines and clinical samples. The overexpression of miR-145 in the PC cell lines, PC3 and DU145, induced apoptosis. Target gene searches have revealed that the pro-apoptotic gene, TNFSF10, is significantly upregulated by the overexpression of $m i R-145$ (17).

We have identified novel pathways of $m i R-145$-mediated suppression of tumor cell invasion and migration in many cancers based on genome-wide gene expression profiles $(18,21)$. In this study, we determined that $m i R-145$ regulates mRNAs in PC cells using gene expression profiling. In our search for miR-145 target genes in PC cells, FSCN1 was the most down-regulated gene. The $m i R-145$ target gene profile of PC cells is in complete accord with our own data on bladder cancer and esophageal cancer cell profiles $(18,21)$. Our results strongly indicate that FSCN1 is a target gene of $m i R-145$ and suggest its important role as an oncogene in human cancer cells.

FSCN1 is an actin-binding protein required for the formation of actin-based cell surface protrusions and cytoplasmic bundles of microfilaments (29). FSCN1 activity is essential for filopodial dynamics, and it has been proposed that fascin imparts rigidity to the forming filopodia to efficiently push the membrane forward (30). Cells with prominent cytoplasmic protrusions as well as actively migrating cells express high levels of FSCN1, whereas this protein is undetectable in most normal epithelial cells (31).

The overexpression of FSCN1 in tumors of the lung (31), prostate (32), esophagus (33), breast (34), colon (35), pancreas (36), ovary (37) and skin (38) usually correlates with high grade, extensive invasion, distant metastasis and poor prognosis. We demonstrate that the silencing of the FSCN1 
A

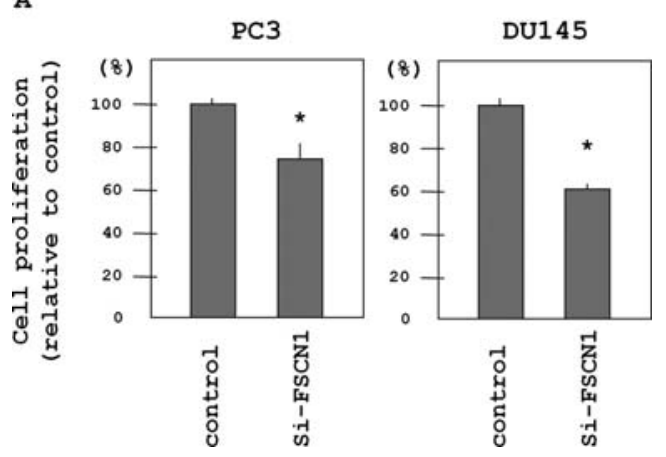

B

$\mathrm{PC} 3$

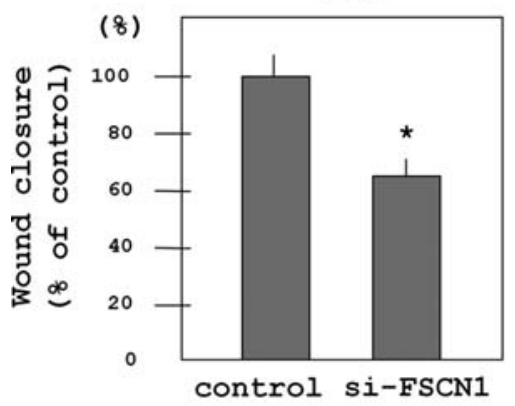

DU145

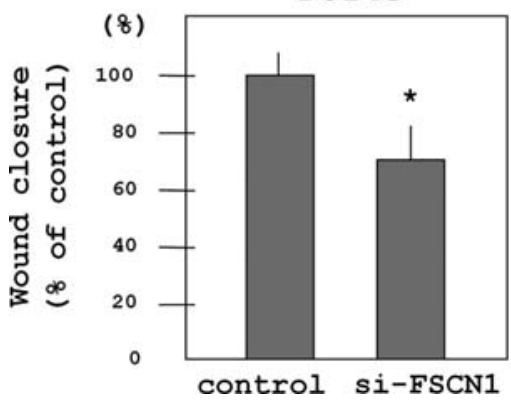

Ohr

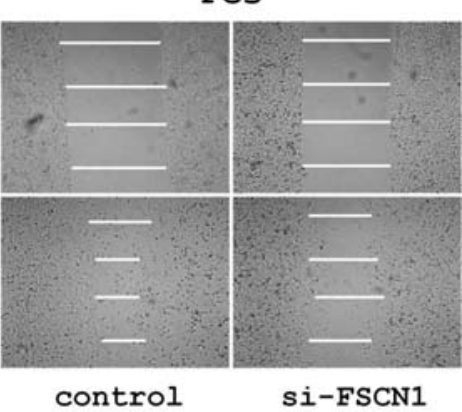

DU145

$\mathrm{Ohr}$

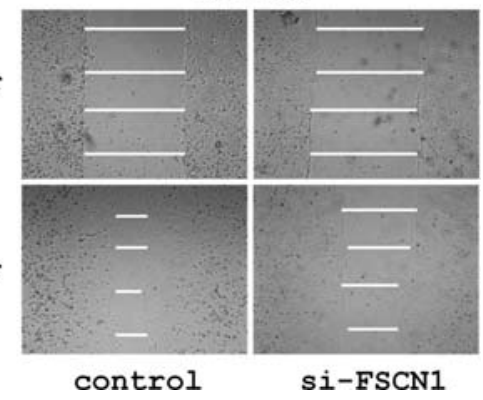

C
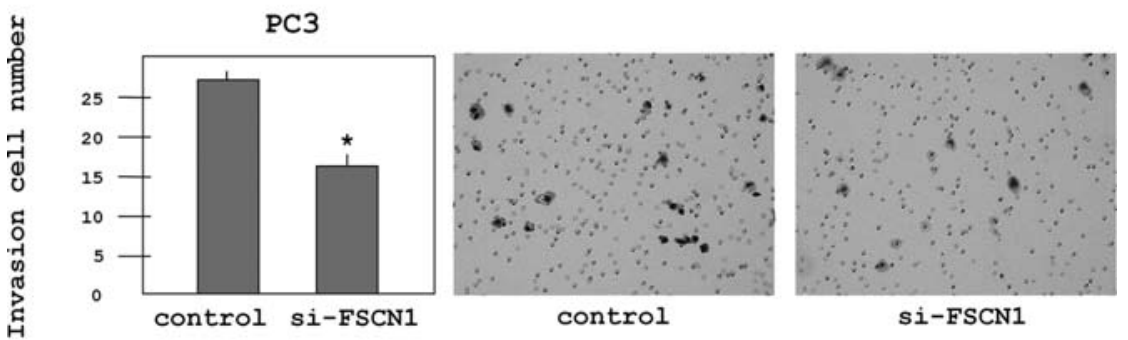

control

Si-FSCN1
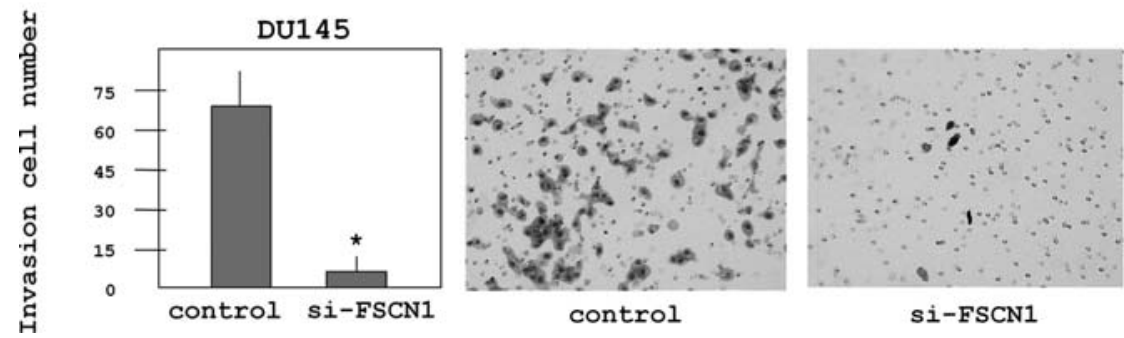

Figure 5. Effects of proliferation, migration and invasion activity in PC cells following si-FSCN1 treatments. (A) Cell proliferation was determined using an XTT assay $72 \mathrm{~h}$ after treatment. The data were standardized against the control cell lines and are presented as relative cell proliferation numbers. "p $<0.05$. (B) Cell migration was evaluated using the monolayer wound healing assay. Quantification of cell migration using the wound healing assay (left panel). Phase micrographs of PC3 and DU145 cells $24 \mathrm{~h}$ after monolayer wound healing (right panel). ${ }^{*} \mathrm{p}<0.05$. (C) Cell invasion was evaluated using the Matrigel invasion assay $48 \mathrm{~h}$ after treatment. Quantification of cell invasion (left panel). Phase micrographs of invading PC3 and DU145 cells (right panel). The data are presented as relative cell invasion numbers and are representative of three independent experiments. ${ }^{*} \mathrm{p}<0.05$. 
gene in PC3 and DU145 cells decreases cell motility and invasion. Similarly, studies have also shown that FSCN1 inhibition reduces tumor growth and lymph node metastasis in DU145 cells in mice. In addition, FSCN1 epithelial expression was significantly up-regulated in localized and hormone-refractory PC compared to benign prostate tissue (32). These results show that the overexpression of FSCN1 contributes to $\mathrm{PC}$ progression and is a potential therapeutic target for this disease.

In summary, our expression profiles in PC cell lines show that FSCN1 can have an oncogenic function and that $m i R-145$ can act as a tumor suppressor through the direct control of FSCN1 expression. The overexpression of FSCN1 contributes to cell migration and invasion in various cancer cells. As the down-regulation of $m i R-145$ and the overexpression of FSCN1 have been commonly identified in many types of cancer, including PC, we suggest that this tumor suppressive miRNA and oncogenic mRNA pathway could be an important therapeutic target in human cancers.

\section{Acknowledgements}

This study was supported by a Grant-in-Aid for Scientific Research (no. 21592187) from the Ministry of Education, Science, Sports and Culture (C).

\section{References}

1. Haas GP and Sakr WA: Epidemiology of prostate cancer. CA Cancer J Clin 47: 273-287, 1997.

2. Johansson JE, Andren O, Andersson SO, Dickman PW, Holmberg L, Magnuson A and Adami HO: Natural history of early, localized prostate cancer. JAMA 291: 2713-2719, 2004.

3. Rubin MA and De Marzo AM: Molecular genetics of human prostate cancer. Mod Pathol 17: 380-388, 2004.

4. Chu KC, Tarone RE and Freeman HP: Trends in prostate cancer mortality among black men and white men in the United States. Cancer 97: 1507-1516, 2003.

5. Jemal A, Siegel R, Ward E, Murray T, Xu J and Thun MJ: Cancer statistics, 2007. CA Cancer J Clin 57: 43-66, 2007.

6. Bartel DP and Chen CZ: Micromanagers of gene expression: the potentially widespread influence of metazoan microRNAs. Nat Rev Genet 5: 396-400, 2004

7. Kloosterman WP and Plasterk RH: The diverse functions of microRNAs in animal development and disease. Dev Cell 11: 441-450, 2006

8. Filipowicz W, Bhattacharyya $\mathrm{SN}$ and Sonenberg $\mathrm{N}$ : Mechanisms of post-transcriptional regulation by microRNAs: are the answers in sight? Nat Rev Genet 9: 102-114, 2008.

9. Lu J, Getz G, Miska EA, Alvarez-Saavedra E, Lamb J, Peck D, Sweet-Cordero A, Ebert BL, Mak RH, Ferrando AA, Downing JR, Jacks T, Horvitz HR and Golub TR: MicroRNA expression profiles classify human cancers. Nature 435: 834-838, 2005.

10. Calin GA and Croce CM: MicroRNA signatures in human cancers. Nat Rev Cancer 6: 857-866, 2006.

11. Ambs S, Prueitt RL, Yi M, Hudson RS, Howe TM, Petrocca F, Wallace TA, Liu CG, Volinia S, Calin GA, Y Pantis HG, Stephens RM and Croce CM: Genomic profiling of microRNA and messenger RNA reveals deregulated microRNA expression in prostate cancer. Cancer Res 68: 6162-6170, 2008.

12. Ozen M, Creighton CJ, Ozdemir M and Ittmann M: Widespread deregulation of microRNA expression in human prostate cancer. Oncogene 27: 1788-1793, 2008.

13. Porkka KP, Pfeiffer MJ, Waltering KK, Vessella RL, Tammela TL and Visakorpi T: MicroRNA expression profiling in prostate cancer. Cancer Res 67: 6130-6135, 2007.

14. Prueitt RL, Yi M, Hudson RS, Wallace TA, Howe TM, Yfantis HG, Lee DH, Stephens RM, Liu CG, Calin GA, Croce CM and Ambs S: Expression of microRNAs and protein-coding genes associated with perineural invasion in prostate cancer. Prostate 68: $1152-1164,2008$.
15. Schaefer A, Jung M, Mollenkopf HJ, Wagner I, Stephan C, Jentzmik F, Miller K, Lein M, Kristiansen G and Jung K: Diagnostic and prognostic implications of microRNA profiling in prostate carcinoma. Int J Cancer 126: 1166-1176, 2010.

16. Tong AW, Fulgham P, Jay C, Chen P, Khalil I, Liu S, Senzer N, Eklund AC, Han J and Nemunaitis J: MicroRNA profile analysis of human prostate cancers. Cancer Gene Ther 16: 206-216, 2009.

17. Zaman MS, Chen Y, Deng G, Shahryari V, Suh SO, Saini S Majid S, Liu J, Khatri G, Tanaka Y and Dahiya R: The functional significance of microRNA-145 in prostate cancer. Br J Cancer 103: 256-264, 2010.

18. Chiyomaru T, Enokida H, Tatarano S, Kawahara K, Uchida Y, Nishiyama K, Fujimura L, Kikkawa N, Seki N and Nakagawa M: miR-145 and miR-133a function as tumour suppressors and directly regulate FSCN1 expression in bladder cancer. $\mathrm{Br} \mathrm{J}$ Cancer 102: 883-891, 2010.

19. Arndt GM, Dossey L, Cullen LM, Lai A, Druker R, Eisbacher M, Zhang C, Tran N, Fan H, Retzlaff K, Bittner A and Raponi M: Characterization of global microRNA expression reveals oncogenic potential of miR-145 in metastatic colorectal cancer. BMC Cancer 9: 374, 2009.

20. Iorio MV, Visone R, Di Leva G, Donati V, Petrocca F, Casalini P, Taccioli C, Volinia S, Liu CG, Alder H, Calin GA, Menard S and Croce CM: MicroRNA signatures in human ovarian cancer. Cancer Res 67: 8699-8707, 2007.

21. Kano M, Seki N, Kikkawa N, Fujimura L, Hoshino I, Akutsu Y, Chiyomaru T, Enokida H, Nakagawa $\mathrm{M}$ and Matsubara $\mathrm{H}$ : miR-145, miR-133a and miR-133b: Tumor suppressive miRNAs target FSCN1 in esophageal squamous cell carcinoma. Int J Cancer 127: 2804-2814, 2010.

22. Akao Y, Nakagawa Y, Kitade Y, Kinoshita T and Naoe T: Downregulation of microRNAs-143 and -145 in B-cell malignancies. Cancer Sci 98: 1914-1920, 2007.

23. Sachdeva M and Mo YY: miR-145-mediated suppression of cell growth, invasion and metastasis. Am J Transl Res 2: 170-180, 2010.

24. Ichimi T, Enokida H, Okuno Y, Kunimoto R, Chiyomaru T, Kawamoto K, Kawahara K, Toki K, Kawakami K, Nishiyama K, Tsujimoto G, Nakagawa M and Seki N: Identification of novel microRNA targets based on microRNA signatures in bladder cancer. Int J Cancer 125: 345-352, 2009.

25. Kikkawa N, Hanazawa T, Fujimura L, Nohata N, Suzuki H, Chazono H, Sakurai D, Horiguchi S, Okamoto Y and Seki N: miR-489 is a tumour-suppressive miRNA target PTPN11 in hypopharyngeal squamous cell carcinoma (HSCC). Br J Cancer 103: 877-884, 2010.

26. Sugimoto T, Seki N, Shimizu S, Kikkawa N, Tsukada J, Shimada H, Sasaki K, Hanazawa T, Okamoto Y and Hata A: The galanin signaling cascade is a candidate pathway regulating oncogenesis in human squamous cell carcinoma. Genes Chromosomes Cancer 48: 132-142, 2009.

27. Shi B, Sepp-Lorenzino L, Prisco M, Linsley P, deAngelis T and Baserga R: Micro RNA 145 targets the insulin receptor substrate- 1 and inhibits the growth of colon cancer cells. J Biol Chem 282: 32582-32590, 2007.

28. Sachdeva M and Mo YY: MicroRNA-145 suppresses cell invasion and metastasis by directly targeting mucin 1 . Cancer Res 70: 378-387, 2010

29. Hashimoto Y, Skacel M and Adams JC: Roles of fascin in human carcinoma motility and signaling: prospects for a novel biomarker? Int J Biochem Cell Biol 37: 1787-1804, 2005.

30. Vignjevic D, Kojima S, Aratyn Y, Danciu O, Svitkina T and Borisy GG: Role of fascin in filopodial protrusion. J Cell Biol 174: 863-875, 2006.

31. Pelosi G, Pasini F, Fraggetta F, Pastorino U, Iannucci A, Maisonneuve P, Arrigoni G, De Manzoni G, Bresaola E and Viale G: Independent value of fascin immunoreactivity for predicting lymph node metastases in typical and atypical pulmonary carcinoids. Lung Cancer 42: 203-213, 2003.

32. Darnel AD, Behmoaram E, Vollmer RT, Corcos J, Bijian K, Sircar K, Su J, Jiao J, Alaoui-Jamali MA and Bismar TA: Fascin regulates prostate cancer cell invasion and is associated with metastasis and biochemical failure in prostate cancer. Clin Cancer Res 15: 1376-1383, 2009.

33. Hashimoto $Y$, Ito $T$, Inoue $H$, Okumura $T$, Tanaka E, Tsunoda $S$, Higashiyama M, Watanabe G, Imamura M and Shimada Y: Prognostic significance of fascin overexpression in human esophageal squamous cell carcinoma. Clin Cancer Res 11: 2597-2605, 2005 
34. Grothey A, Hashizume R, Sahin AA and McCrea PD: Fascin, an actin-bundling protein associated with cell motility, is upregulated in hormone receptor negative breast cancer. Br J Cancer 83: 870-873, 2000.

35. Jawhari AU, Buda A, Jenkins M, Shehzad K, Sarraf C, Noda M, Farthing MJ, Pignatelli $\mathrm{M}$ and Adams JC: Fascin, an actinbundling protein, modulates colonic epithelial cell invasiveness and differentiation in vitro. Am J Pathol 162: 69-80, 2003.

36. Maitra A, Adsay NV, Argani P, Iacobuzio-Donahue C, De Marzo A, Cameron JL, Yeo CJ and Hruban RH: Multicomponent analysis of the pancreatic adenocarcinoma progression model using a pancreatic intraepithelial neoplasia tissue microarray. Mod Pathol 16: 902-912, 2003.
37. Lin CK, Chao TK, Yu CP, Yu MH and Jin JS: The expression of six biomarkers in the four most common ovarian cancers: correlation with clinicopathological parameters. APMIS 117: $162-175,2009$.

38. Goncharuk VN, Ross JS and Carlson JA: Actin-binding protein fascin expression in skin neoplasia. J Cutan Pathol 29: 430-438, 2002. 